\title{
Halitosis y colutorios orales. Revisión de la literatura
}

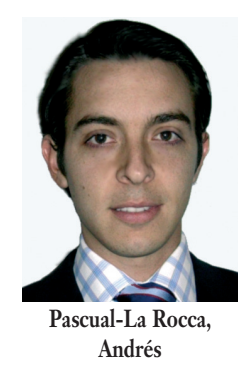

\author{
Halitosis and mouthwashes. Revision of medical literature
}

\section{Pascual-La Rocca, Andrés* Savoini, Marzia* Santos, Antonio**}

\footnotetext{
* Máster en Periodoncia U.I.C. Profesor Asociado Máster Periodoncia, Universidad Internacional de Cataluña. ** Director del Área de Periodoncia de la Universidad Internacional de Cataluña.
}

\section{Correspondencia}

Andrés Pascual La Rocca

Universitat Internacional de Catalunya Área de Periodoncia

C/ Josep Trueta s/n

08190 Sant Cugat del Vallès.
Resumen: La halitosis viene siendo descrita en la literatura desde hace muchos años, pero sólo en los últimos años se le ha dado una importancia profesional significativa. Existen numerosos factores localizados y sistémicos causantes del mal olor oral. Sin embargo, según se trate de una u otra causa podemos estar ante condiciones transitorias, como en Ios casos del hambre, de un bajo nivel de saliva durante el sueño, de restos alimenticios o de prescripción de drogas o tabaco.

En caso de halitosis patológicas crónicas, las causas pueden ser de origen oral o no.

Algunos estudios han demostrado que la producción de olor es el resultado del metabolismo de bacterias Gram

El tratamiento y control del mal olor bucal debe enfocarse a determinar la causa del problema y a discernir su origen, ya sea médico y/o dental. Desde el punto de vista odontológico, el mejor tratamiento consiste en estimular al paciente a mantener una correcta higiene oral. Procedimientos comunes como la profilaxis y el raspado radicular pueden ser efectivos en los pacientes en los que la causa del mal olor es la periodontitis.

Para combatir el mal olor bucal mediante un método químico han sido utilizados varios tipos de enjuagues bucales. El uso de colutorios será recomendado según su grado de eficacia científicamente comprobada.

Palabras clave: Halitosis, Mal olor oral, Mal aliento, Aceites Esenciales, Clorhexidina.

Abstract: Halitosis has been described in medical literature for many years, but it has only recently received professional recognition.

Several local and systemic factors can cause oral malodour: Some of these factors are transient such as hunger, low salivary flow during sleep, retention of food debris, prescription of some drugs or tobacco consumption.

Pathologic chronic situations can have oral and systemic conditions.

Clinical and laboratory trials have demonstrated that the odour results from the metabolism of gram- bacteria.

Treatment and control of oral malodour must be directed to the medical and/or oral origin of the cause. The treatment must focus on controlling and stimulating the oral hygiene of the patient. Prophylaxis, scaling and root planing therapies, are proven to be effective in cases related to periodontal disease.

Different mouthwashes have been used in the chemical therapy of halitosis. The recommendation for mouthwash must be determined by the efficiency of the product.

Key words: Halitosis, Oral malodour, Bad breath, Essential oils, Chlorhexidine.

BIBLID [1138-123X (2005)10:4; julio-agosto 369-496]

Pascual-La Rocca A, Savoini M, Santos A. Halitosis y colutorios orales. Revisión de la literatura. RCOE 2005;10(4):417-425. 


\section{Introducción}

Halitosis es el término que describe todo olor desagradable procedente del aire espirado, sin tomar en cuenta el origen o sustancias que lo producen ${ }^{1 *}$. A lo largo de la historia y desde tiempos antiguos, se ha hecho referencia a esta condición con diversos nombres como fetor ex ore, mal aliento o mal olor oral. Sin embargo, no ha recibido la importancia que merecía hasta años recientes, cuando se ha comenzado a estudiar en proporción a su importancia clínica y social.

Tras una encuesta en el año 1995 la ADA (Asociación Dental Americana) advirtió que entre el 40 y el $50 \%$ de los odontólogos asistían en ese país una media de siete pacientes semanales que referían sufrir de halitosis ${ }^{2}$. Este hecho demuestra que no sólo se trata de una condición referente a la salud, sino que también posee ciertas repercusiones sociales debido a la importancia de la imagen personal y de las relaciones interpersonales ${ }^{3 * *}$.

A pesar de la gran importancia que esta cuestión ha adquirido en la actualidad, no existe un conocimiento adecuado por parte de la mayoría de profesionales a la hora de abordar el problema, lo que podría deberse a que no existen criterios universales estandarizados que permitan definir al paciente afectado por esta condición. Sin embargo, la cantidad de información referente a la halitosis va en aumento gracias al gran número de investigaciones que se han emprendido en busca de respuestas. Autores como Nachnani ${ }^{4}$, subrayan la importancia del diagnóstico y el tratamiento de la halitosis en los programas de estudio de las Facultades de
Medicina y Odontología con el fin de que las generaciones venideras de clínicos puedan abordar efectivamente el tratamiento de esta condición.

\section{Etiología}

En la actualidad se considera una teoría multifactorial de las halitosis en la que puede hacerse referencia a una o varias causas que pueden tener un origen oral o no.

La detección del mal olor se puede lograr por diferentes métodos, que más adelante se comentarán en profundidad, pero la verdadera dificultad podría estar en la detección de la causa.

Debemos comenzar por distinguir entre una "halitosis genuina» $\mathrm{y}$ "pseudo-halitosis». El primer término es utilizado para hacer referencia a los casos en los que el mal olor es real y puede ser fácilmente diagnosticado por diferentes métodos, mientras que en la "pseudo-halitosis" el mal olor no existe, pero el paciente está convencido de padecerlo. En ambos casos, si tras un tratamiento exitoso el paciente cree padecer aún el problema se hará uso del termino "halitofobia» ${ }^{5 *}$.

La halitosis genuina a su vez puede ser subdividida en:

Halitosis fisiológica, o también llamada transitoria, es una halitosis autolimitada y asociada a diferentes condiciones y procesos transitorios, como la disminución o detención del flujo de saliva durante el sueño inhibiendo la autoclisis de la cavidad oral. También se incluye el uso de ciertas drogas y medicamentos, así como los estados de ayuno y el tabaco. Se trata de un problema principalmente cos- mético y no de salud que no impide la vida normal al individuo.

De manera independiente haremos referencia en esta división a la halitosis causada por aporte sanguíneo. En estos casos, los compuestos volátiles son absorbidos al torrente sanguíneo desde cualquier lugar del cuerpo, y posteriormente son transferidas al alveolo pulmonar. Estos compuestos son excretados en concentraciones significativas en el aire espirado, pudiendo provocar halitosis. Un ejemplo de estos casos sería la halitosis tras la ingesta de alimentos como el ajo y la cebolla.

Halitosis patológica. Es de evolución crónica, y persiste a pesar de las técnicas de higiene oral. Puede tener su origen en la cavidad oral o no. Entre las causas de origen oral más comunes encontramos la enfermedad periodontal y la acumulación de placa en el dorso de la lengua ${ }^{6} 0$ alteraciones patológicas de xerostomía, como es el caso en pacientes irradiados o con síndrome de Sjögren. En diferentes estudios clínicos se han asociado también otras condiciones infecciosas orales, como la gingivitis ulceronecrotizante aguda (CUNA), la pericoronitis, la alveolitis seca, y las úlceras y aftas orales.

Las causas de origen extraoral incluyen alteraciones patológicas del sistema respiratorio, ya sea del tracto superior, como la sinusitis crónica, la obstrucción nasal, el absceso nasofaríngeo y el carcinoma de laringe, o del tracto inferior, como la bronquitis, bronquiectasias, neumonías, abscesos pulmonares y carcinomas de pulmón; tambien puede ser debido a patologías del aparato digestivo, como los casos 
de gastritis y úlcera. Además, existen otras alteraciones del metabolismo enzimático y de transporte capaces de producir compuestos volátiles causantes de halitosis. Dentro de este grupo se incluyen causas como la cetosis diabética, alteraciones renales y hepáticas, carcinomas y leucemias.

La interpretación de los diferentes tipos de halitosis puede contribuir al diagnóstico de la patología base.

Son varios los investigadores y autores que se han centrado en la búsqueda de una respuesta al interrogante acerca del origen y causa de la halitosis, y la mayoría de los resultados coinciden en señalar que en la mayor parte de los casos tiene un origen oral y sólo un bajo porcentaje tiene su origen fuera de esta cavidad ${ }^{5 * *}$.

\section{Factores asociados}

Una vez valoradas las diferentes causas asociadas, es necesario explicar las condiciones y factores por los cuales se produce la halitosis.

En la actualidad el consenso referido en la literatura señala que el olor desagradable en la halitosis se debe a la presencia de gases olorosos que principalmente se asocian a la producción de sulfuros en la hidrólisis de proteínas a aminoácidos como la cisteina, cistina y metionina en el metabolismo de microorganismos Gram$5^{5^{* *}}$. Los principales compuestos volátiles de sulfuro (CVS) relacionados con la halitosis son dimetil sulfuro [( $\left.\left.\mathrm{CH}_{3}\right)_{2} \mathrm{~S}\right]$, metil mercaptano $\left(\mathrm{CH}_{3} \mathrm{SH}\right)$, sulfuro de hidrógeno $\left(\mathrm{H}_{2} \mathrm{~S}\right)$ y dióxido de sulfuro $\left(\mathrm{SO}_{2}\right)$. Otros grupo de gases libres de sulfuro también han sido aislados y señalados en la litera- tura, como las aminas putrecina y cadaverina, compuestos aromáticos volátiles, como indole y skatole, y ácidos orgánicos como el acético y el propiónico.

\section{Implicación bacteriana y nichos}

Independientemente del origen de la halitosis, las bacterias representan un importante papel en la producción del mal olor. El estudio de McNama$\mathrm{ra}^{7}$ demostró mediante técnicas de incubación de saliva la presencia de una flora de predominio Gram- asociada a la formación de componentes malolorosos.

Otros autores han buscado la asociación de bacterias específicas, entre las que encontramos especies como Fusobacterium, Veillonella, T. denticola, P. gingivalis, Porfiromonas endodontalis, bacteriodes y peptoestreptococcus.

Entre los posibles nichos bacterianos capaces de alojar las bacterias involucradas encontramos las criptas amigdalinas o los senos paranasales en casos de sinusitis. Pero el principal deposito bacteriano corresponde a la parte posterior del dorso de la lengua ${ }^{5^{* *}}$. El dorso de la lengua parece ser el nicho microbiológico humano más complejo. La estructura anatómica de la lengua parece favorecer la formación de un biofilm bacteriano complejo en el que se encuentran con frecuencia bacterias periodontales ${ }^{8}$.

La presencia de placa bacteriana en el dorso lingual está directamente ligada a la presencia de bacterias y por lo tanto a producción de $\mathrm{CVS}^{9}$.
El estudio de Tonzetich y $\operatorname{cols}^{10}$ demostró la reducción en los valores de compuestos volátiles de sulfuro en el aire espirado tras la eliminación de la placa lingual.

Debemos recordar que la composición de la placa lingual no sólo comprende bacterias. También estan presentes células epiteliales descamadas y células sanguíneas que favorecen la adhesión bacteriana y proveen sustratos para el metabolismo de las mismas.

Si bien es cierto que la principal causa de halitosis es la placa lingual, no debemos olvidar que la enfermedad periodontal tiene etiología bacteriana. En los diferentes estadios de la enfermedad periodontal se ha podido encontrar una correlación con la halitosis ${ }^{10}$.

Mediante análisis por cromatografía de gases, Yaegaki ${ }^{11}$ llegó a la conclusión de que el dorso de la lengua era la principal fuente de bacterias productoras de CVS en los casos de periodontitis inicial o moderada, pero que en los casos de periodontitis severas las principales responsables eran las bacterias de la bolsa periodontal. Cabe resaltar que los principales agentes asociados son el metilmercaptano y el sulfuro de hidrógeno, los cuales, aparte de producir un olor desagradable, son tóxicos a los tejidos en mínimas concentraciones, por lo que podrían ser un agente importante en las condiciones inflamatorias establecidas en la periodontitis.

\section{Diagnóstico}

El diagnóstico de la halitosis no ha llegado al "Cold Standard" que nos 


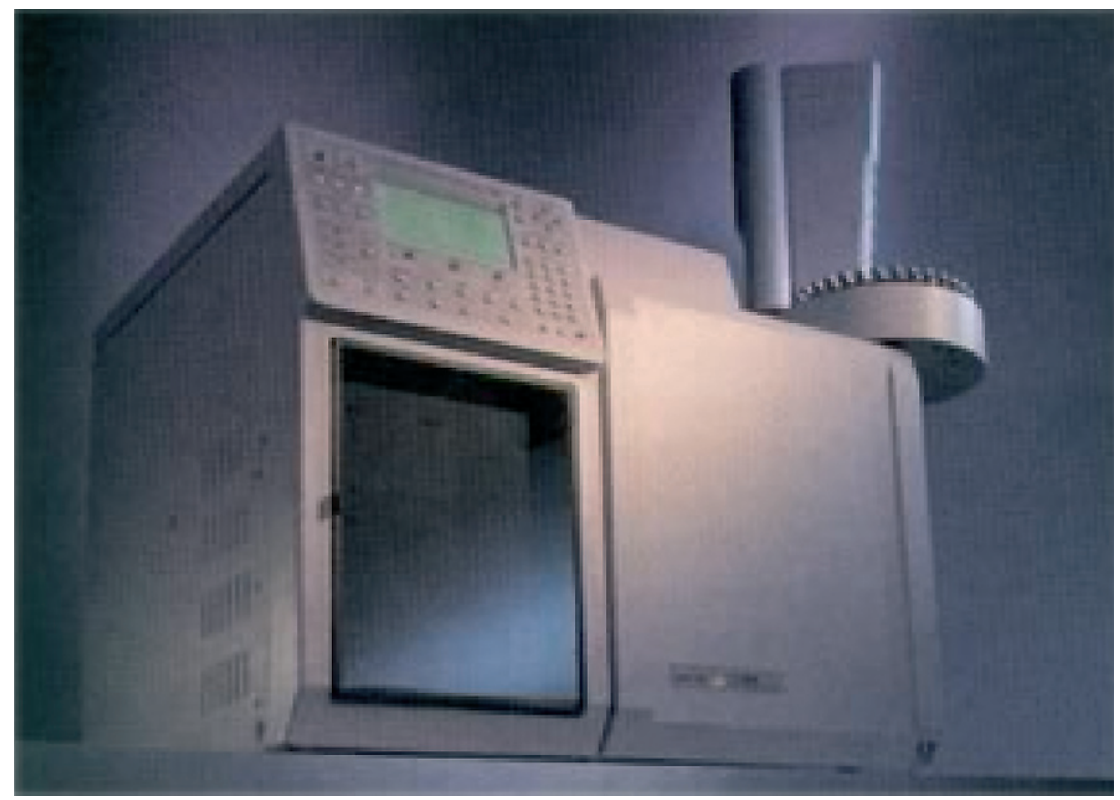

Figura 1. Cromatografia de Gases.

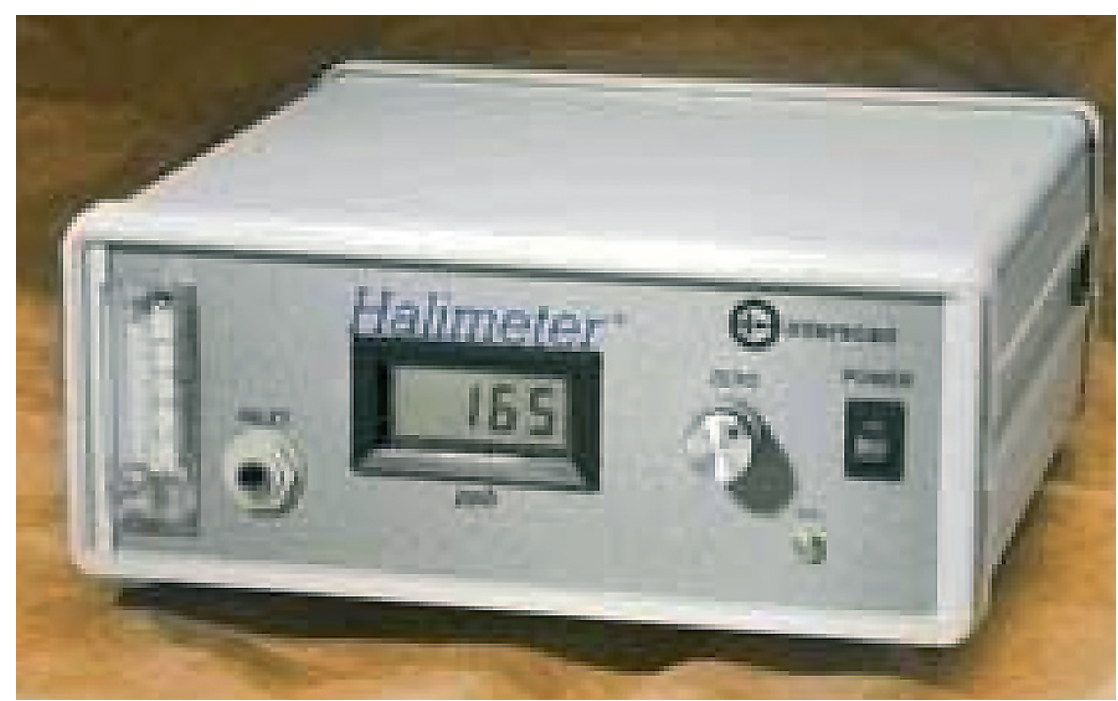

Figura 2. Monitor portátil de sulfuros.

permitiría una medición rápida y correcta. Sin embargo, existen diversas posibilidades que se agrupan básicamente en tres conjuntos: las mediciones organolépticas, la cromatografía de gases y la monitorización de sulfuro.

\section{Mediciones organolépticas}

Consisten, básicamente, en el olfato directo del aire emanado de la cavidad oral. La valoración la realizará el propio individuo por auto "feedback», o bien un juez experto en olores.
Su reproducibilidad y objetividad son escasas, pero son el procedimiento más frecuentemente realizado debido a que no se necesita un instrumental especial. Las mediciones se hacen en base a una escala analogica propuesta en el International Workshop on Oral Halitosis (1999). El nivel 0 representa ausencia de olor, siguiendo la escala numérica hasta llegar al 5, que representa un mal olor extremo. Resultaría idóneo contar con jueces entrenados para reconocer y tasar el mal olor; sin embargo, existen muchos factores que pueden modificar la prueba. Debemos recordar que la percepción del olor es más aguda en las mujeres, por lo que podrían ser mejores jueces; por otra parte, la capacidad olfatoria disminuye con el aumento de la edad. Obviamente, el propio juez podría estar acostumbrado al olor por padecer él mismo de halitosis o por trabajar en un medio rodeado de olores como el caso de los odontólogos ${ }^{12}$

Sobre esta técnica se han descrito variaciones, como oler el revestimiento lingual previamente eliminado con un raspador o cucharilla, o la autoevaluación ${ }^{13}$, lamiendo la muñeca y oliendo.

\section{Mediciones con instru- mental}

\section{Cromatografía de gases}

Es el instrumento más cercano al «Gold Standard» en cuanto a la medición de la halitosis. Esto se debe a que es el único instrumento capaz de hacer una medición cuantitativa diferenciando los distintos gases encontrados ${ }^{5 * *}$. Es de extrema precisión, siendo capaz de percibir concentraciones muy bajas. Asímismo, presenta ciertas desventajas, como la dificultad de movilización, un 


\begin{tabular}{|c|c|c|}
\hline \multicolumn{3}{|c|}{ Tabla l. Clasificación de los pacientes para ofrecer el trałamiento adecuado [Yaenahi] } \\
\hline Clasificación & $\begin{array}{l}\text { Necesidad de } \\
\text { tratamiento }\end{array}$ & Descripción \\
\hline 1. Halitosis Cenuina & & Mal Olor obvio con una intensidad mayor al nivel socialmente aceptable \\
\hline IA. Halitosis Fisiológica & NT-1 & $\begin{array}{l}\text { 1. El mal olor se desarrolla por procesos de putrefacción en la cavidad oral. } \\
\text { No existe una enfermedad o condición patológica especifica asociada. } \\
\text { 2. El origen se encuentra principalmente en la zona posterior del dorso de } \\
\text { la lengua. } \\
\text { 3. Deberían excluirse factores temporales como la dieta. }\end{array}$ \\
\hline \multicolumn{3}{|l|}{ IB. Halitosis Patológica } \\
\hline Oral & NT-1 y NT-2 & $\begin{array}{l}\text { 1. Halitosis causada por alguna enfermedad, condición patológica o alte- } \\
\text { ración en la función de los tejidos orales. } \\
\text { 2. Se incluye la halitosis originada del revestimiento lingual, modificado } \\
\text { por condiciones patológicas (Ej. Enf. periodontal, xerostomia, etc.) }\end{array}$ \\
\hline Extraoral & NT-1 y NT-3 & $\begin{array}{l}\text { 1. Mal olor con origen, nasal, perinasal, y/o laringeo. } \\
\text { 2. Mal olor con origen en el tracto respiratorio o digestivo superior. } \\
\text { 3. Mal olor originado por desórdenes en cualquier parte del cuerpo. } \\
\text { El olor es transportado por vía sanguínea y eliminado en los pulmo- } \\
\text { nes. (Ej. Diabetes, hepatocirrocis, uremia, ulceras gástricas, etc.) }\end{array}$ \\
\hline II. Pseudo-Halitosis & TN-1 y TN-4 & $\begin{array}{l}\text { 1. Mal olor obvio no percibido por otos, pero el paciente está convencido } \\
\text { de su existencia. } \\
\text { 2. La condición mejora al aconsejar al paciente (literatura de soporte, edu- } \\
\text { cación, explicación y examen de resultados) y con el uso de técnicas de } \\
\text { higiene oral }\end{array}$ \\
\hline III. Halitophobia & NT-1 y NT-5 & $\begin{array}{l}\text { 1. tras el tratamiento exitoso de halitosis genuina o pseudohalitosis, el } \\
\text { paciente continúa creyendo que padece de halitosis. } \\
\text { 2. No existe evidencia física o social que sugiera que la halitosis está pre- } \\
\text { sente. }\end{array}$ \\
\hline
\end{tabular}

elevado costo, el tiempo necesario para el procesamiento de la muestra y el manejo del equipo por un operador capacitado $^{3^{* *}}$. Debido a estas razones, el cromatógrafo de gases ha sido desplazado del uso clínico y limitado a la investigación ${ }^{13}$.

\section{Monitor portátil de sulfuros}

Es el equipo más usado en los últimos años para la valoración de la halitosis. Permite analizar el contenido total de sulfuros presentes en el aire de la boca, pero entre sus inconveniente encontramos que no permite hacer diferencia entre los distintos sulfuros, siendo altamente sensible al sulfuro de hidrógeno, pero poco sensible al metil mercaptano ${ }^{5 *}$. Además, el equipo puede perder precisión con el uso, haciéndose necesarias calibraciones periódicas ${ }^{3 * *}$

Tras evaluar 75 individuos mediante pruebas organolépticas y un monitor de sulfuro, Rosenberg ${ }^{14}$ concluyó que la cuantificación de CVS con el uso del monitor portátil provee resultados rápidos y objetivos en la valoración de la halitosis.

Como ventajas encontramos la posibilidad de incorporarlo al equipo de la clínica dental gracias a sus razonables dimensiones y a la ausencia de dificultad en su manejo, además, de no tener un costo elevado.

\section{Nariz electrónica}

Es un dispositivo que permite la aspiracion de gases y a través de un 
patrón de algoritmos es capaz de clasificar los compuestos presentes. Se aplica actualmente en el diagnóstico de la halitosis, sin embargo en el estudio de Tanaka y cols ${ }^{15}$, se compararon los resultados obtenidos con este instrumento con los resultados de pruebas organolepticas, demostrando un buen nivel de correlacion, lo que sugiere que su uso podria ser de utilidad en la evaluacion de la halitosis.

\section{Tratamiento}

La falta de consenso en el diagnóstico se refleja en el tratamiento de la halitosis. Los protocolos clínicos varían mucho, a la hora de buscar el tratamiento, establecer el correcto diagnóstico y determinar si las causas son de origen oral o no ha de ser el principal objetivo.

Intentando agrupar a los pacientes en conjuntos para ofrecer el tratamiento adecuado, Yaegaki ${ }^{5 * *}$ propone la siguiente clasificación (tabla 1).

Divide las necesidades de tratamiento en 5 clases (tabla 2), donde la NT-1 es un remedio específico para las halitosis con origen fisiológico, pero también aplicable en todos los otros casos, lo que hace evidente que la detallada explicación y la enseñanza de una correcta higiene oral son claves en el tratamiento de todas las halitosis ${ }^{16}$

Entre estas técnicas de higiene debemos reforzar un correcto cepillado y el uso de la seda dental. Lo principal, no obstante, será la limpieza lingual, puesto que la halitosis suele tener su origen en ella debido a las condiciones que anteriormente mencionamos, es lógico pensar que al

\begin{tabular}{|ll|}
\hline & Tabla e. Necesidades de tralamiento segín Yaenahi \\
\hline Categoría & Descripción \\
\hline NT-1 & Explicación sobre la halitosis e instrucciones higiene. \\
\hline NT-2 & $\begin{array}{l}\text { Profilaxis oral, limpieza profesional, tratamiento de enferm- } \\
\text { edades orales especialmente enfermedad periodontal. }\end{array}$ \\
\hline NT-3 & Referir al especialista. \\
NT-4 & Explicar los resultados del examen, instrucciones profesiona- \\
\hline NT-5 & Referir al psicólogo, psiquiatra u otro especialista psicológico \\
\hline
\end{tabular}

mantenerla limpia disminuirá el número de CVS. En la limpieza podemos hacer uso de raspadores linguales o el mismo cepillo de dientes, realizando los movimientos desde la zona posterior hacia la más anterior.

Otro elemento de gran importancia en la terapia de la halitosis corresponde al control químico mediante antimicrobianos. Los enjuagues con eficacia comprobada deben ser capaces de mantener un balance entre la flora normal y el sobrecrecimiento de las bacterias patógenas. La mayoría de las fórmulas comerciales sólo enmascaran el olor y proveen una acción antiséptica muy limitada ${ }^{3 * *}$. A pesar de la presencia de estas sustancias antimicrobianas en su contenido, los efectos no son duraderos ${ }^{17}$.

Para combatir el mal olor bucal mediante un método químico, se han utilizado varios tipos de enjuagues bucales. Su comercialización y promoción se da principalmente como coadyuvantes en el control del aliento, y éste parece ser su principal motivo de uso.

Al ser considerados la mayoría productos cosméticos ${ }^{18}$, antes de poder ser comercializados no son sometidos a las mismas regulaciones que los medicamentos. Es por esto que la re- comendación profesional se hará según el grado de eficacia científicamente comprobada.

Entre los antisépticos disponibles en el mercado para combatir el mal olor se incluyen:

\section{Peróxido de hidrógeno}

El uso de $\mathrm{H}_{2} \mathrm{O}_{2}$ en el control de la halitosis fue presentado en un estudio sobre 20 pacientes con enfermedad periodontal. Tras enjuagar con peróxido de hidrógeno al 0,75\% se observó una disminución de hasta un $90 \%$ en los niveles de CVS que se mantenían durante un periodo de hasta 120 minutos $^{19}$. Pero no debemos olvidar que su uso se asocia a patologias que no son motivo de esta revisión.

\section{Enjuagues con zinc}

Disponible en forma de citrato, acetato y cloruro. Este tipo de enjuagues son efectivos al combatir el mal olor.

El ión de zinc actúa como inhibidor del olor al prevenir la reducción del grupo disulfuro a tilos, y al reaccionar con los grupos tilos presentes en los $\mathrm{CVS}^{3+*}$

En un estudio comparativo, Nachnani ${ }^{20}$ demostró que los enjuagues con zinc eran superiores en el 
control de la halitosis en comparación con enjuagues de clorhexidina al usarlos dos veces al día durante 60 segundos por un periodo de seis semanas.

\section{Enjuagues de clorhexidina}

Existen múltiples autores que coinciden en los efectos positivos que tiene el uso de la CHX en la disminución de los valores de halitosis ${ }^{21}$. La clorhexidina es el mejor agente antiplaca y antigingivitis que se conoce hoy en día, pero su eficacia en el tratamiento del mal olor no ha sido estudiada extensivamente, tal vez porque su uso no debe ser extendido por un periodo prolongado de tiempo debido a sus múltiples efectos secundarios $^{2}$.

Rosenberg comparó que el uso de CHX al 0,2\% producía una reducción de hasta un $43 \%$ en la reducción total de CVS y disminuian hasta un $50 \%$ los valores de las pruebas organolépti$\operatorname{cas}^{17}$.

En el estudio de Roldan ${ }^{22}$, tras enjuagar con una fórmula de $\mathrm{CHX}$ al 0,05\% más cloruro de cetylpyridinium al $0,05 \%$ y lactato de zinc al $0,14 \%$, se demostró la reducción del número de bacterias en tres nichos orales, y, por lo tanto su efectividad en el tratamiento de la halitosis

En un estudio de Quirynen y cols ${ }^{23}$ sobre estudiantes de Odontología, se comparó la efectividad de tres formulaciones en el control de los CVS tras la supresión de técnicas de higiene oral. Las formulaciones consistían en $\mathrm{CHX}$ al 0,05\% más alcohol; $\mathrm{CHX}$ al $0,05 \%$, cloruro de cetylpyridinium y $0,14 \%$ de lactato de zinc; y un tercer grupo fluoruro estañoso (125ppmf). Tras siete días, las tres formulaciones demostraron ser efectivas en la reducción de los valores de CVS y sobre la carga bacteriana en la saliva, así como en el retraso en la formación de nueva placa.

Rosenberg ${ }^{24}$, comparó un enjuague en dos fases de agua/aceite que contenía bajas concentraciones de cetylpyridinium con un enjuague de CHX al 0,2\% y un placebo. Los resultados probaron mayor efectividad de la CHX en la reducción de valores de CVS.

\section{Triclosán}

Es una molécula no iónica de amplio espectro. Al ser una sustancia disolvente de lípidos es efectiva contra muchos tipos de bacterias. Combinaciones de zinc con triclosán en forma de enjuague han demostrado efectividad debido a un efecto acumulativo: la reducción del mal olor progresa con la utilización del producto ${ }^{17}$

Hay diversos estudios en los que se evalúa el efecto de la molécula de triclosán en la disminución de CVS. La mayoría de estos estudios evalúan su uso asociado a pastas dentífricas; sin embargo existen otros en los que se valora su efectividad en colutorios. Young ${ }^{25}$ demostró con técnicas de incubación de saliva humana, que la producción de CVS dependía de la administración de triclosán.

Existe evidencia científica que demuestra que los solventes utilizados en el transporte de la molécula de triclosán, pueden afectar el efecto anti CVS, como en el caso de aceites, detergentes sin cargas y chromophor, mientras que si se utiliza lauril sulfato, polipropileno glicol o agua su efecto se mantiene intacto.

\section{Compuestos fenólicos "aceites esenciales"}

El producto bucal más antiguo es el Listerine ${ }^{\circledR}$, (Pfizer Consumer Healthcare, Morris Plains, NJ, EEUU), un compuesto de fenol y aceites esenciales de timol y eucaliptol mezclados con metilsalicilato en un vehículo hidroalcohólico al 26,9\%. El mecanismo de acción tradicional de los compuestos fenólicos es por disrupción e inhibición de las enzimas bacterianas, actuando además sobre la pared celular de las bacterias. Sin embargo, también existen algunas evidencias de que el fenol y el alcohol contenido en estos compuestos pueden extraer los lipopolisacáridos derivados de las endotoxinas de las bacterias gram negativas ${ }^{26}$.

Se han demostrado los efectos antimicrobianos in vivo de los colutorios a base de aceites esenciales. Se ha evaluado también su capacidad en la reducción del mal olor oral y se ha encontrado que tiene la habilidad de suprimir las bacterias odoríferas, eliminando así los compuestos volátiles de sulfuro de la cavidad bucal'17. En un estudio sobre la flora del espacio subgingival generadora de mal olor, 30 adultos sanos sin afecciones bucodentales evidentes fueron asignados al azar a efectuar un único enjuague durante 30 segundos bajo supervisión con un colutorio a base de aceites esenciales (Listerine ${ }^{\circledR}$ ), un enjuague placebo (un vehículo con hidroalcohol) o un enjuague de control (agua destilada normal). Los enjuagues placebo y de control se utilizaron para distinguir los efectos del alcohol de los aceites esenciales (Pitts y cols ${ }^{17}$ ). El colutorio a base de aceites esenciales redujo de forma considerable la cantidad de bacterias de los espa- 
cios subgingivales generadoras de mal olor en todas las muestras tomadas después del tratamiento y demostró ser muy eficaz para reducir todos los determinantes de halitosis de tipo bucal. También se demostró que el colutorio a base de aceites esenciales destruye de forma eficaz las bacterias de los espacios interproximales difíciles de alcanzar. El recuento de bacterias generadoras del mal olor de los espacios subgingivales fue considerablemente menor en el caso de Listerine en todas las muestras tomadas con posterioridad al tratamiento $(p \leq 0,05)^{16}$.

En un estudio reciente de $\mathrm{Koz}$ lovsky y cols $^{27}$ se demostró que un colutorio a base de aceites esenciales reducía la cantidad de bacterias generadoras de mal olor y las puntuaciones organolépticas durante periodos de dos horas.

Actualmente existe una nueva presentación de aceites esenciales transportados en una película de pululan, Listerine Actives ${ }^{\circledR}$ (Warner Lambert Pfizer). Se colocan en el dorso de la lengua y se disuelven al contacto con la saliva, observándose actividad antimicrobiana local ${ }^{28}$. Recientemente, hemos finalizado un estudio piloto en la Universidad Internacional de Cataluña confirmando la actividad antimicrobiana de esta nueva presentación de aceites esenciales.

\section{Otras opciones}

Existen otros agentes antimicrobianos referidos en la literatura entre los que encontramos el dióxido de cloro, el peróxido de carbamida o la sanguinarina. También existen remedios naturales a base de algas, como la espirulina, pero, en general, su uso no es frecuente. Dichos productos tienen hasta la fecha poca evidencia científica.

En la literatura se hace referencia a una gran diversidad de productos, entre los que encontramos, pastillas, chicles y mentas que son capaces de actuar en la reducción de la halitosis, pero, que muestran básicamente un efecto cosmético.

\section{Conclusiones}

El control de la halitosis debe comenzar por su correcto diagnóstico, pudiendo así adaptar el tratamiento a cada paciente según las necesidades de cada caso.

Es un elemento clave, y debe ser el primer enfoque, lograr educar al paciente en la importancia de los controles de higiene oral, ya que de esta manera podemos asegurarnos el éxito.

En la literatura encontramos diferentes antimicrobianos que han sido ya evaluados, pero la mayoría de los estudios son a corto plazo. A pesar de haber quedado patente su capacidad en la reducción de los valores de halitosis, se hace necesario realizar estudios longitudinales que demuestren el efecto a largo plazo de los mismos.

Es de gran importancia valorar la halitosis en su justa medida y ofrecer un tratamiento consecuente a nuestros pacientes.

\section{Bibliografía recomendada}

Para profundizar en la lectura de este tema, el/los autor/es considera/an interesantes los artículos que aparecen señalados del siguiente modo: *de interés ** de especial interés.

1 *. Rosemberg M. Clinical assessment of bad breath: current concepts. J Am Dent Assoc 1996; 127:475-82.

Este artículo presentó una puesta al día, que se ha convertido en referencia para muchos autores en la actualidad. Presenta generalidades y conceptos de importancia en el tema.

2. Survey conducted at ADA reveals interesting trends. Dent Econ 1995;6: (FALTAN PÁGINAS)

3**. Sans M, Roldan S, Herrera D. Fundamentals of breath malodour. J Contemp Dent Pract 2001;15(2):1-17.
Exelente revision bibliografica. Una de las más completas en este tema, en años recientes. En el podemos encontrar conceptos, clasificación, manejo y tratamiento de la patología.

4. Nachnani, S. Oral malodor - A detailed Review. Disponible en: http://www.halimeter.com/nachnani1.htm. Acceso en 1 agosto 2004.

$5^{* *}$. Yaegaki K, Coil JM. Examination, classification, and treatment of halitosis; clinical perspectives. J Can Dent Assoc 2000;66:257-61. Es un artículo de referencia a la hora de clasificar la patología. El autor hace una de las clasificaciones más validas encontradas en la literatu- re en base a las características del individuo afectado.

6. Tonzetich J. Production and origin of oral malodor: a review of mechanisms and methods of analisis. J Periodontol 1992;63:783-9.

7. McNamara TF, Alexander JF, Lee M. The role of microrcanisms in the production of oral malodor. Oral Surg Oral Med Oral Pathol 1972;34:41-8

8. Roldan S, Herrera D, Sanz M. Biofilms and the tongue: therapeutical approaches for the control of halitosis. Clin Oral Investig 2003; 7:189-97. 
9. Yaegaki K, Sanada K. Volatile sulfur compounds in mouth air from clinically healthy subjects and patients with periodontal disease. J Periodontal Res 1992;27: 233-8.

10. Tonzetich J, Ng SK. Reduction of malodor by oral cleansing procedures. Oral Surg Oral Med Oral Pathol 1976;42:172-81

11. Yaegaki K, Sanada K. Volatile sulphur compounds in mouth air from clinically healthy subjects and patients of periodontal disease. J Perio Res 1992;27:233-8.

12. Rosenberg M. Measurement of Malodor: current methods and future prospects. J Periodontol 1992;63:776-82.

13. Rosenberg M, Kozlovsky A, Gelernter I y cols. Self-estimation of oral malodor. J Dent Res 1995; 74:1577-82.

14. Rosenberg M, Septon I, Eli I y cols. Halitosis measurement by an industrial sulphide monitor. J Periodontol 1991;62:487-9.

15. Tanaka M, Anguri H, Nonaka A y cols. Clinical Assessment of Oral Malodor by the Electronic Nose System J Dent Res 2004;83:317-21

16. Yaegaki K. Tongue brushing and mouth rinsing as basic treatment measures for halitosis. Int Dent J 2002;52:192-6.
17. Pitts G, Brogdon C, Hu L, Masurat T, Pianotti R, Schumann P. Mechanism of action of antiseptic, antiodor mouthwash. J Dent Res 1983 62:738-42

18. Loesche WJ. The effects of antimicrobial mouthrinses on oral malodour and their status relative of U.S. Food and Drug Administration regulations. Quintessence Int 1990; 30:311-8.

19. Takeky K, Masatake T, Harumi S, Tetsuichiro S. Reduction of Bad Breath From Periodontal Patients by Dilute Hydrogen Peroxide Solution. Bull Tokyo Dent Coll 1978;19:209-16.

20. Nachnani S, Anson D. Effect of Orasan on periodontitis and oral malodor. (abstract). Disponible en: http://www.usdentek.com/pro researc.htm\#orasan. Acceso 1 agosto de 2004.

21. Rosenberg M, McCulloc CA. Measurement of oral malodor: Current Methods and future prospects. J Periodontol 1992;63:776-82.

22. Roldán S, Winkel EG, Herrera D, Sanz M, Van Winkelhoff AJ. The effects of a new mouthrinse containing cholrhexidine, cetylpyridinium chloride and zinc lactate on the microflora of oral halitosis patients: a dual centre, double-blind placebo-controlled study. J Clin Periodontol 2003;30:427-34.
23. Quirynen M, Avontroodt P, Soers C. The efficacy of amine fluoride stannous fluoride in the suppression of morning breath odour. J Clin Periodontol 2002; 29:944-54.

24. Rosenberg M, Gelernter I, Barki M, Bar-Ness R. Day long reduction of oral malodor by a twoPhase oil:water mouthrinse as compared to chlorhexidine and placebo rinses. J Periodontol 1992;63:39-43.

25. Young A, Jonski G, Rolla G. A study of triclosán and its solubilizers as inhibitors of oral malodour. J Clin Periodontol 2002;29:107881.

26. Fine DH, Letizia J, Mandel ID. Effect of rinsing with Listerine antiseptic on the properties of developing dental plaque. J Clin Peridontol 1985;12(8): 660-6.

27. Kozlovsky A, Goldberg S, Natour I, RogatkyGat A, Gelernter I, Rosenberg M. Efficacy of a 2-phase oil:water mouthrinse in controlling oral malodour, gingivitis and plaque. J Periodontol 1996;67:577-82.

28. Borden LC. Anti-Oral Malodour Efficacies of Novel Essential-Oil Containing Breath Films. J Dent Res 79 (IADR Abstracts) 2000; 405 (abstract 2095) 